\title{
Commentary Empiric anti-Candida therapy for patients with sepsis in the ICU: how little is too little?
}

\author{
Yoav Golan
}

Division of Geographic Medicine and Infectious Diseases, Tufts Medical Center, 800 Washington Street, Boston, MA 02111, USA

Corresponding author: Yoav Golan, ygolan@tuftsmedicalcenter.org

Published: 21 August 2009

Critical Care 2009, 13:180 (doi:10.1186/cc7977)

This article is online at http://ccforum.com/content/13/4/180

(c) 2009 BioMed Central Ltd

See related research by Zilberberg et al., http://ccforum.com/content/13/3/R94

\begin{abstract}
Prior analyses suggest that empiric fluconazole for ICU patients with sepsis is cost-effective. Using updated estimates of efficacy and cost, Zilberberg and colleagues compare the use of micafungin with that of fluconazole. The authors conclude that micafungin is an attractive alternative to fluconazole. This conclusion is driven by recent reduction in micafungin's cost and by better activity of micafungin against azole-resistant Candida species. Their results are limited by inflated estimates of efficacy, life expectancy and risk of Candida sepsis. This commentary explores the rationale for early anti-Candida strategies in the ICU and highlights the contribution and limitations of the article by Zilberberg and colleagues.
\end{abstract}

In their article in Critical Care, Zilberberg and colleagues examine the cost-effectiveness of empiric anti-Candida treatment for ICU patients with sepsis [1]. Over the past decade, Candida has emerged as an invasive pathogen in many ICUs [2-4]. The case-fatality rate for Candida blood-stream infections is substantially higher than that for bacterial bloodstream infections [5]. Exploring the reasons for such a trend, Kumar and colleagues [6] compared a large number of severe sepsis episodes caused by bacteria or Candida. Despite their high severity of illness and in contrast to patients with bacterial sepsis, most of those with Candida sepsis did not receive effective treatment within 24 hours of hypotension. Although the overall case-fatality rate was higher among those with Candida sepsis, the case-fatality rate among those who received early anti-Candida therapy was substantially lower and comparable to that seen in bacterial sepsis [6]. These data suggest that the early initiation of empiric anti-Candida treatment is life saving.

The initiation of empiric anti-Candida therapy to patients with sepsis represents a tradeoff. On one hand, it can increase the survival rate among those infected with Candida. On the other hand, it increases costs and, possibly, the risk of drugrelated toxicity, drug-drug interactions, and emergence of antifungal resistance [7]. Clinicians caring for ICU patients with sepsis frequently wonder in which circumstances is the administration of an empiric anti-Candida agent advisable? Which agent is most attractive? Similar to other clinical questions, the best experimental design to evaluate treatment strategies is the clinical trial. But like any trial that evaluates an empiric strategy, the required sample size, and, therefore, the cost and ability to enroll enough patients, are often prohibitive. When data from clinical trials are not available, an alternative research design needs to be utilized.

Decision analysis is used to compare the effectiveness and cost of alternative interventions and to identify the most effective strategy that has an acceptable cost-effectiveness ratio. When reliable data are available and standard methodology is employed, the results of decision analysis can help guide clinicians. The epidemiology of bacterial and Candida sepsis in the ICU is well described and estimates of the effectiveness and cost of anti-Candida agents are available. Thus, questions such as those related to the initiation of empiric anti-Candida agents in the ICU can be answered using decision analysis.

Because Candida is only one of several pathogens that cause sepsis in ICU patients, the empiric administration of an anti-Candida agent would result in exposure to anti-Candida therapy for many patients with non-Candida sepsis. While only those with Candida sepsis can benefit, all can be harmed by toxicity. Thus, to be considered a reasonable candidate, the anti-Candida agent should have low toxicity. In the past, the benefit from antifungals such as amphotericin deoxycholate or its lipid preparations was balanced by substantial toxicity [7-8]. With the recent availability of safer anti-Candida agents, the triazoles and echinocandins, empiric therapy became a viable approach. A 2005 analysis determined that the empiric use of a safe anti-Candida agent would increase the survival of ICU patients with suspected 
infection and no response to three days of anti-bacterials [8]. In that analysis, empiric caspofungin was the most effective strategy but its cost in 2005 was high, resulting in empiric fluconazole as the preferred strategy. Several critical factors have changed since 2005. Additional echinocandins have been approved, their cost has substantially decreased, and, in many ICUs, isolates of Candida from blood-stream infections are now less susceptible to fluconazole [2]. Thus, the article by Zilberberg and colleagues, which uses current estimates, is relevant and timely.

Zilberberg and colleagues conclude that empiric micafungin is a cost-effective alternative to empiric fluconazole. Given that both agents have low toxicity, this conclusion is driven by differences in drug cost and in efficacy. The authors calculated that empiric micafungin saves more lives than empiric fluconazole. This better efficacy is based on the assumption that micafungin is active against fluconazoleresistant Candida species. The authors consider Candida krusei or Candida glabrata as fluconazole resistant. But data from clinical trials show that 50 to $60 \%$ of C. glabrata isolates are treatable by fluconazole when administered at the dose used in Zilberberg and colleagues' analysis [9-10]. As a result, the estimate used in Zilberberg and colleagues' analysis inflates the efficacy difference and biases the analysis in favor of micafungin.

Additional factors that determine the cost-effectiveness of empiric anti-Candida strategies are the proportion of ICU sepsis that is caused by Candida and the life-expectancy of Candida sepsis survivors. For both, larger estimates support the use of costly anti-Candida agents. The authors assume that $14 \%$ of ICU sepsis episodes are caused by Candida. This estimate is higher than the 5 to $10 \%$ estimate described in recent literature and is based upon studies that included the isolation of Candida from the lungs and other clinically irrelevant sites as representing 'Candida sepsis' $[2,6,11]$. To estimate the life expectancy of an ICU survivor, the authors use actuarial tables that reflect life expectancy in the general population, and adjust them for increased mortality related to sepsis. But survivors of an ICU-acquired sepsis have a substantially lower life expectancy compared to age-matched representatives of the general population $[12,13]$. These overestimations exaggerate the affordability of empiric micafungin.

Nevertheless, the main finding of this study by Zilberberg and colleagues is encouraging. The reduction in the acquisition cost of micafungin, as well as that of other echinocandins, has made these effective anti-Candida agents more affordable. Additional data and improved estimates will help refine the best empiric anti-Candida strategy for ICU patients with sepsis.

\section{Competing interests}

$Y G$ has received research funding and is on the advisory board for Merck and Pfizer. YG is also a consultant and on the speakers' bureau for Merck and Astellas Pharmaceuticals.

\section{Refrences}

1. Zilberberg MD, Kothari S, and Shorr AF: Cost-effectiveness of micafungin as an alternative to fluconazole empiric treatment of suspected ICU-acquired candidemia among patients with sepsis: A model simulation. Crit Care 2009, 13:R94.

2. Martin GS, Mannino DM, Eaton S, Moss M: The epidemiology of sepsis in the United States from 1979 through 2000. N Engl J Med 2003, 348:1546-1554.

3. Pfaller MA, Diekema DJ: Epidemiology of invasive Candidiasis: a persistent public health problem. Clin Microbiol Rev 2007, 20:133-163.

4. Wisplinghoff $H$, Bischoff $T$, Tallent SM, Seifert $H$, Wenzel RP, Edmond MB: Nosocomial bloodstream infections in US hospitals: analysis of 24,179 cases from a prospective nationwide surveillance study. Clin Infect Dis 2004, 39:309-317.

5. Gudlaugsson O, Gillespie S, Lee K, Vande Berg J, Hu J, Messer S, Herwaldt L, Pfaller M, Diekema D: Attributable mortality of nosocomial candidemia, revisited. Clin Infect Dis 2003, 37: 1172-1177.

6. Kumar A; CATSS Study Group: The high mortality of Candida septic shock is explained by excessive delays in initiation of antifungal therapy. In Proceedings of the 47th Interscience Conference on Antimicrobial Agents and Chemotherapy. September 17-20, 2007; Chicago, IL. Washington DC: American Society of Microbiology. Abstract K-2174.

7. Bates DW, Su L, Yu DT, Chertow GM, Seger DL, Gomes DR, Dasbach EJ, Platt R: Mortality and costs of acute renal failure associated with amphotericin B therapy. Clin Infect Dis 2001, 32:686-693.

8. Golan Y, Wolf MP, Pauker SG, Wong JB, Hadley S: Empirical anti-Candida therapy among selected patients in the intensive care unit: a cost-effectiveness analysis. Ann Internal Med 2005, 143:857-869.

9. Reboli AC, Rotstein C, Pappas PG, Chapman SW, Kett DH, Kumar D, Betts R, Wible M, Goldstein BP, Schranz J, Krause DS, Walsh TJ; Anidulafungin Study Group: Anidulafungin versus fluconazole for invasive candidiasis. N Engl J Med 2007, 356: 2472-2482.

10. Rex JH, Pappas PG, Karchmer AW, Sobel J, Edwards JE, Hadley S, Brass C, Vazquez JA, Chapman SW, Horowitz HW, Zervos M, McKinsey D, Lee J, Babinchak T, Bradsher RW, Cleary JD, Cohen DM, Danziger L, Goldman M, Goodman J, Hilton E, Hyslop NE, Kett DH, Lutz J, Rubin RH, Scheld WM, Schuster M, Simmons B, Stein DK, Washburn RG: A randomized and blinded multicenter trial of high-dose fluconazole plus placebo versus fluconazole plus amphotericin B as therapy for candidemia and its consequences in nonneutropenic patients. Clin Infect Dis 2003, 36:1229-1231.

11. Xie GH, Fang XM, Fang $Q$, Wu XM, Jin $Y H$, Wang JL, Guo $Q L$, Gu MN, Xu OP, Wang DX, Yao SL, Yuan SY, Du ZH, Sun YB, Wang $\mathrm{HH}$, Wu SJ, Cheng BL: Impact of invasive fungal infection on outcomes of severe sepsis: a multicenter matched cohort study in critically ill surgical patients. Crit Care 2008, 12:R5.

12. Flaatten $H$, Kvale $R$ : Survival and quality of life 12 years after ICU. A comparison with the general Norwegian population. Intensive Care Med 2001, 27:1005-1011.

13. Niskanen $M$, Kari $A$, Halonen $P$ : Five-year survival after intensive care - comparison of 12,180 patients with the general population. Finnish ICU Study Group. Crit Care Med 1996, 24:19621967. 